\title{
Chapter 14 \\ Strengthening the Capacity \\ on Geospatial Information Technology and Earth Observation Applications
}

\author{
Rajesh Bahadur Thapa, Poonam Tripathi, Mir A. Matin, \\ Birendra Bajracharya, and Betzy E. Hernandez Sandoval
}

\subsection{Introduction}

The innovative transformation in geospatial information technology (GIT) and Earth observation (EO) data provides a significant opportunity to study the Earth's environment and enables an advanced understanding of natural and anthropogenic impacts on ecosystems at the local, regional, and global levels (Thapa et al. 2015; Flores et al. 2019; Leibrand et al. 2019; Chap. 1). The major advantages of these technologies can be briefly categorized into five broad areas: multidisciplinary; innovative and emerging; providing platforms for analysis, modelling, and visualization; capability to support decision-making; and impact on policies (Shrestha and Bajracharya 2002; Revenga 2005; Thapa et al. 2014; Xia et al. 2014; Nelson et al. 2019). As such, EO can support solutions by supplying information on trends via spatiotemporal monitoring and can also assist in disaster early warning and response. On the other hand, GIT can deliver analysis and modelling of potential resource-related supply-and-demand scenarios, evaluate impacts, and provide visualization to relay information and assist the end users in decision making-all of this would contribute towards achieving the sustainable development goals (Ofori-Amoah 2008; Manfré et al. 2012; Ingole et al. 2015; Scott and Rajabifard 2017). Currently, the profound impact of EO and GIT is recognized worldwide, including in the $\mathrm{HKH}$ region, where it plays a significant role in monitoring, investigating, and evaluating processes such as land use and land cover change, deforestation, vegetation growth, disaster risk and damage, forest fire, and glacier dynamics in the context of climate resilience (Chap. 1). However, research in these aspects needs a more robust understanding so as to effectively implement

R. B. Thapa $(\bowtie) \cdot$ P. Tripathi · M. A. Matin · B. Bajracharya

International Centre for Integrated Mountain Development (ICIMOD), Kathmandu, Nepal

e-mail: rajesh.thapa@icimod.org

B. E. Hernandez Sandoval

NASA SERVIR Science Coordination Office, Huntsville, AL, USA

(C) The Author(s) 2021

B. Bajracharya et al. (eds.), Earth Observation Science and Applications for Risk

Reduction and Enhanced Resilience in Hindu Kush Himalaya Region,

https://doi.org/10.1007/978-3-030-73569-2_14 
science-based policies and management processes. The HKH region is an extremely diverse area; it also hosts the highest mountain range in the world and is known for its highly rugged terrains that pose a daunting challenge of accessibility to collect and manage data and information. It's here the combination of GIT and EO has an important role to play-they provide access to remote regions and offer feasible ways to address critical data and information gaps.

That said, the region lacks enough professionals and trained specialists in EO and GIT (Thapa et al. 2019; Chap. 3). The progressive development of these technologies demands rapid support via building capacity through education, training, and developing more professionals and specialists. For this purpose, on the one hand, a strategic framework is required to meet the challenge of providing a well-trained workforce, and on the other, the trained professionals ought to be encouraged to apply their knowledge in various spheres. The SERVIR-HKH program (Chap. 1) is working on bridging such gaps in the region and aims to: strengthen the ability of governments and other development stakeholders to incorporate EO and GIT into the decision-making process; promote free and open information sharing through national and regional platforms and collaborations; develop innovative, user-tailored analyses, decision-support products, and trainings that advance scientific understanding; and deliver information to those who need it. Capacity building is one of the key pillars of the SERVIR program. In this chapter, we present SERVIR-HKH's capacity building approach and its implementation in the $\mathrm{HKH}$ region, as also its achievements and the lessons that have been learnt along the way.

\subsection{Capacity Gap in the Region: A Brief Outlook}

In order to successfully develop and implement capacity development activities, we need to understand the basic requirements of the national institutions and the end users so that they can utilize and apply such knowledge in the decision-making process. The emergence and advancement in technologies and their innovative applications also generate certain capacity building needs. In this regard, various consultation workshops have been organized by SERVIR-HKH in Afghanistan, Bangladesh, Nepal, and Pakistan (Chap. 3). During these consultation workshops, the participants were asked a set of guiding questions on data, capacity, and services related to their countries. The feedback from the groups were summarized, assessed, and ranked on a priority basis. The basic priorities, requirements, and gaps were identified in terms of: data and knowledge; capacity gap and gender disparity; and lack of institutional and technical capacities. The data and knowledge gaps generally pointed to the lack of human resources, geospatial capacity, infrastructure, and data availability. The capacity gap in terms of EO and GIT in the HKH is large due to the lack of an appropriate strategy to sustain long-term projects; this leads to challenges in maintaining and improving the infrastructure, updating geospatial data, and in strengthening human resources after the completion of projects (Thapa 
et al. 2019). In addition, the involvement and participation of women in the EO and GIT fields is rather low in the region (Tripathi and Thapa 2019) although the significant role of gender and gender-responsive policy agendas and decisions is well recognized (Chap. 15).

The assessment of the institutions across the countries in the region showed varying degrees of geospatial capacities in terms of GIT infrastructure and human resources. The needs also varied. For instance, most of the institutions in Bangladesh indicated that they needed hydroclimatic data more frequently to develop an early warning system for riverine floods, flash floods, abnormal water surges in the coastal areas, and to assess related vulnerabilities such as riverbank erosion, crop loss, and landslides; while institutions in Nepal mentioned that they needed data based on elevation as there were several variables in terms of land and climate; the Afghanistan institutions stated that their agencies mostly used annual data to produce geospatial products for irrigation planning and for assessing the impacts of hazards such as droughts, floods, and landslides. The data requirements may also be of daily, seasonal, or annual in nature to perform various types of spatial analysis and to produce map products and services. As mentioned earlier, many institutions in the region are lacking strategies for the sustainability of GIT projects, as the majority of geospatial applications are project-based, thereby creating challenges for upgrading GIT infrastructure and updating geospatial data and enhancing the skills of human resources after the completion of projects. There is also a knowledge gap in terms of EO and GIT applications at the decision- and policymaking levels, apart from the issue of poor data-sharing provisions among the institutions. For instance, Pakistan's capacity and infrastructure in geospatial technologies are fairly good, but there are lack of platforms available for the sharing of data and products beyond products a single institution. Overall, in the HKH region, there is a need to build geospatial capacities (infrastructural as well as by way of human resources). Therefore, strategic and systemic capacity building pathways for individuals and institutions in the region are a prerequisite.

\subsection{Capacity Building Pathways}

The key capacity development dimensions have been identified at three levels: individual capacity - this deals with changing attitudes and behaviors by imparting knowledge and skills via training; Institutional capacity - this focuses on overall performance and operational proficiency (i.e., by way of developing instructions, tools, guidelines, and an information management system) to assist and catalyze organizational changes; and systemic - this enables the creation of a conducive environment and assists in effectively reflecting the capacity in decision-making, i.e., in terms of policy, economy, and accountability (Shrestha and Bajracharya 2002; GEF 2003; Potter and Brough 2004; UNDP 2008; Chandler and Kennedy 2015). Here it must be emphasized that the process of building capacity is iterative, involving design, application, knowledge, and modification. Thus, based on a 


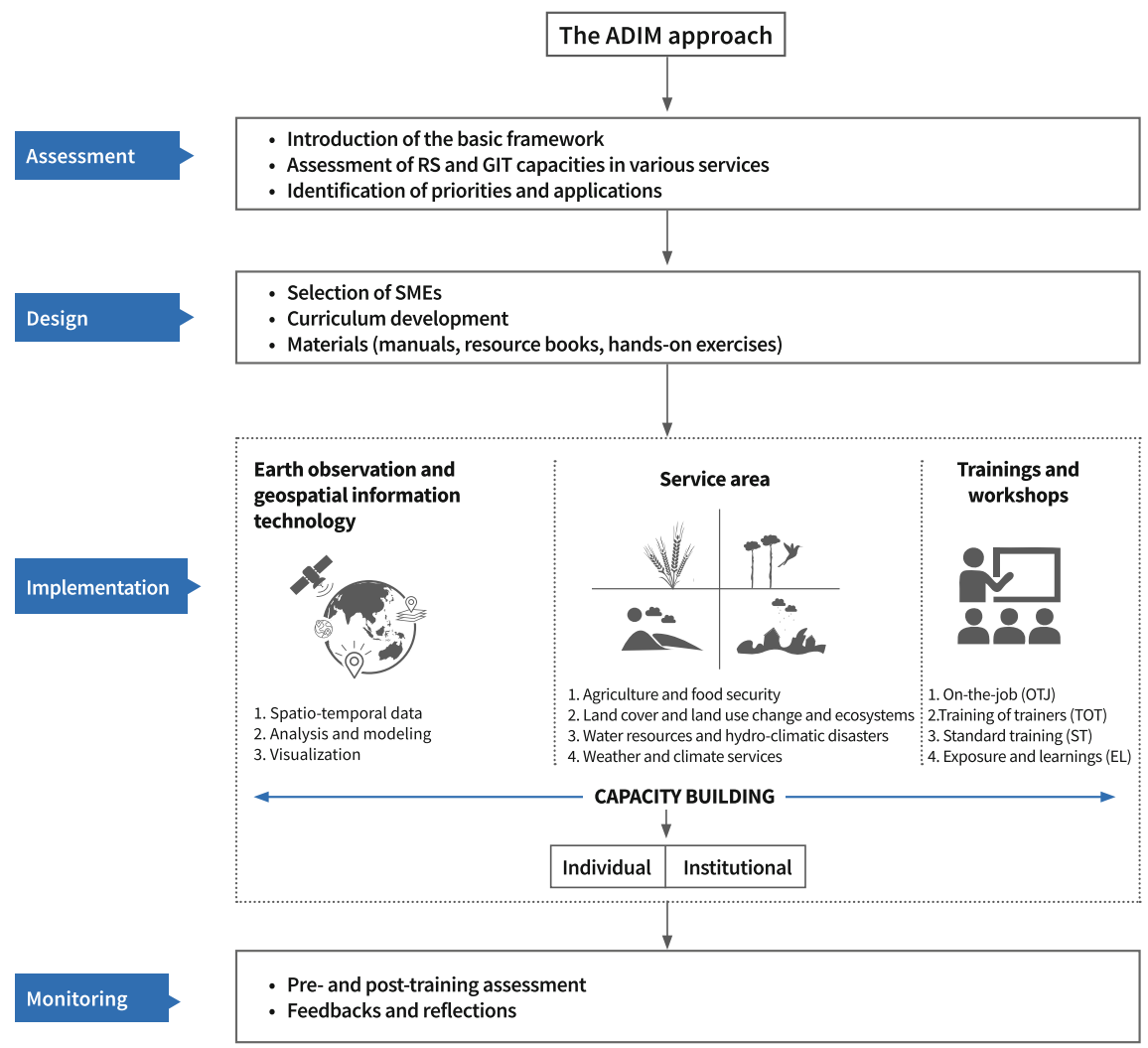

Fig. 14.1 Capacity building framework within SERVIR-HKH

situational analysis of the $\mathrm{HKH}$ region and acknowledging the lessons that were learnt, the ADIM approach was developed, which addresses Assessment, Design, Implementation, and Monitoring (Thapa et al. 2019). This is briefly presented in Fig. 14.1.

\subsubsection{Capacity Assessment}

As capacity needs differ among various institutions at the regional and national levels, it is essential to assess the existing capacity and future needs to determine the priorities at various levels in order to design effective plans. It can be characterized as analyzing the preferred capacity compared to the existing one and offering systematic methods to gather critical information and data on the capacity resources and needs. This is the pillar of any capacity development formulation that addresses the demands and needs to strengthen and optimize the existing capacity; it therefore 
incorporates such steps as mobilization and design, conduct and summarization, and then interprets the assessment results. So, various country consultation workshops were organized along these lines during the years 2015 and 2016 in Afghanistan, Pakistan, Bangladesh, and Nepal. These workshops helped in the systematic assessment of gaps, needs and priorities, as well as evaluated the capacities of each country (Chap. 3). These gaps and needs were subsequently grouped into the four major thematic areas of SERVIR: agriculture and food security (AFS); land use, land cover, and ecosystems (LULC\&E); water resources and hydro-climatic disasters (WRHD); and weather and climate services (WCS). This assessment process played a significant role in promoting active user engagement, ongoing partnerships, and in identifying more engagements and partners; it also served as an input for our capacity development pathways.

\subsubsection{Capacity Building Design}

The appropriate designing of capacity building interventions is crucial during the formulation phase. The emphasis here is on strategic thinking based on innovations to ensure that the implementation methodology is more progressive and effective with an adaptive vision to utilize emerging technologies such as SAR, GEE, machine learning, cloud computing, and open access tools. After the assessment process, the key design considerations involve priority issues, key opportunities, sequenced activities, and a realistic selection of activities. For this purpose, consultations were held with the subject matter experts (SMEs) and the priority issues were selected as part of the implementation aspect. Four major types of capacity building activities were identified which would enhance the individual, institutional, and systemic capacities at national and regional levels: on-the-job training (OJT); standard training (ST); training of trainers (ToT); and exposure and learning (EL). The OJT and ToT exercises were considered as institutional capacity building activities, while the other two were seen as individual capacity building activities (Thapa et al. 2019).

The OJT activities were semi-structured, focusing on enhancing the capacity of partner institutions to develop, operate, and maintain specific applications and services. They had been designed keeping in mind the background knowledge and skills of the participants who then worked with the SMEs on a rotational basis and learnt how to carry out certain tasks. Upon completion of the training (a period of one to two weeks), the participants were assigned to work independently on the target applications that needed to be completed in a certain time period. The ToTs were focused on training the teaching staff and were aimed at institutional capacity building in order to reach out to more participants via academic institutions. This training lay emphasis on content, skills, knowledge, and effective communication and presentation skills; it also got the participants to develop exercises and refine the materials with local data. The ST module focused on general GIT and EO perspectives and their applications on specific subjects; this module saw the 
participation of professionals from diverse fields. The EL segment imparted awareness on recent developments and applications in GIT and EO and also explained the benefits and prospects of these technologies. All these short-term trainings were primarily targeted at career-seeking youngsters and senior managers for exposure; they were thus exposed to academic and technical exchanges during professional conferences, workshops, and competitions. SERVIR-HKH also worked closely with the thematic SMEs to design a curriculum that incorporated aspects such as learning objectives, expected outcomes, target audience, and daily agenda. Besides, the development of various theoretical and practical materials, including training modules, manuals, reading materials, hands-on exercises, and PPTs, were part of this phase.

\subsubsection{Implementing Capacity Building Activities}

This phase of the ADIM approach refers to the execution of the capacity building activities wherein the four modules of ToT, OJT, ST, and EL were offered to the participants. They were then divided into three categories: policymakers/decision makers; technical professionals; and youth. The policymakers and decision makers formed the top level of the hierarchy; they represented leadership and were the ones who could influence the capacity of GIT and EO services in partner institutions. The technical professionals represented the middle level of the hierarchy and would be mostly involved in the development of databases and in the application of GIT and EO in different thematic areas; so, they were the one who would prepare the products to be used by the leaders. The youth, while representing the lower level of the hierarchy, were nevertheless accorded high importance since they were the ones who needed to be aware and convinced of the recent technology; they were the ones who would be able to forge networks during climate emergencies (Thapa et al. 2019).

Meanwhile, various national- and regional-level collaborative activities took place in capacity building in partnership with local institutions of partner countries and the private sector. In line with ICIMOD's Midterm Action Plan-IV (MTAP-IV) for 2018-2022, SERVIR-HKH has been aiming to overcome the persistent gender inequalities in all sectors by identifying these inequalities and the gaps in addressing them; it has been proactive in redressing the discriminatory social and gender norms and has also been tackling the practices, attitudes, and power relations that help in the prevalence of such norms. (A more elaborate account of SERVIR-HKH's gender-inclusion strategies is discussed in Chap. 15.) In a nutshell, in terms of capacity building, ICIMOD has been focusing on the following areas: providing training on the methods and tools for gender-disaggregated data collection and analysis; enhancing the tools of gender analysis; building women's leadership by proactively including them in equal numbers in trainings, workshops; encouraging young women professionals and students to take to this discipline; fostering "gender champions" in SERVIR-HKH; and collaboratively developing and testing services with the targeted groups. 


\subsubsection{Monitoring and Evaluating the Impact of Capacity Building Activities}

Fundamentally, monitoring and evaluation $(\mathrm{M} \& \mathrm{E})$ is the measurement that helps to interpret the performance of capacity building approaches; it takes into consideration such aspects as design, implementation, learning, performance, and the impact of capacity building pathways. And while monitoring implies an ongoing measurement, evaluation is a periodic measurement (Ortiz and Taylor 2009; Chap. 18). In the area of capacity building and its effectiveness, M\&E gives priority to the following two points: clarity of purpose, i.e., for what, why, and for whom; the nature of the information that is required and choose the way in which data have to be collected-for example, by way of a well-conceived and targeted survey questionnaire. The M\&E process pays attention to both short- and long-term indicators; while the short-term indicators give insights into specific actions and steps and show whether a particular capacity building effort has worked or not, the long-term ones seek to describe the results of a particular capacity building activity over a period of time.

Long-term monitoring under the SERVIR-HKH program follows the Planning, Monitoring, Evaluation, and Learning (PMEL) framework based on the Theory of Change (ToC) and Participatory Impact Pathway Analysis (PIPA) (Chap. 18). As for short-term monitoring, it looks at the capacity that has already been built; here, pre- and post-assessment surveys are conducted for each activity (excluding exposure and learning) in order to gauge the participant's expectations, skills, and knowledge, and also to get their feedback on improving the approach. For this purpose, pre- and post-training evaluation surveys were conducted so as to know whether the participants had improved their knowledge and skills in the subject matter. The surveys were composed of three different sections: basic information and expectations from the participants (pre-assessment) and the relevance of the training for different topics (post-assessment); the incorporation of scientific knowledge - this related to self-assessment of the basic knowledge on the subject and assessing the technical skills related to the subject; and feedback and reflection, wherein the responses were mapped via four levels of knowledge and skills _ “Low/No", "Basic", "Intermediate/Relatively High", and "Advanced/High".

\subsection{Mapping the Impact Pathways}

Mapping the impact of capacity building activities is a key indicator of successful implementation; it provides a means to map the direct and indirect cause-and-effect linkages. Figure 14.2 presents the impact pathway of the ADIM approach and shows significant capacity development in the HKH region. This is briefly discussed below. 


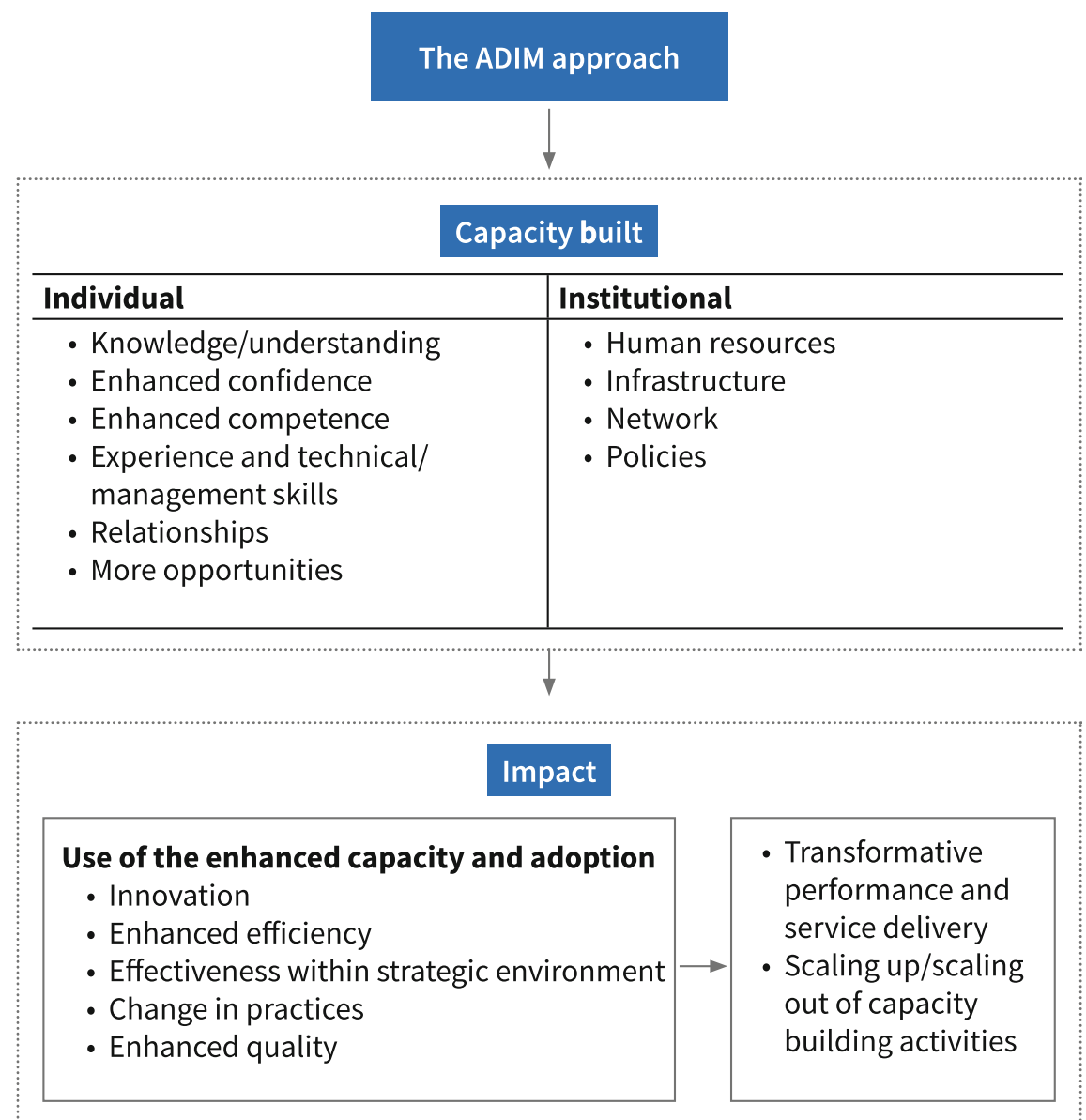

Fig. 14.2 The capacity building impact framework

\subsubsection{Training Modules, Contents and Materials}

Based on the needs assessment and country consultation workshops, an elaborate development of the capacity building modules under the four thematic areas was carried out (Table 14.1). In addition to these four thematic areas, the common needs and priorities of all the countries were captured under a crosscutting theme. In SERVIR-HKH Phase II, all the topics under the thematic areas were secured within 27 distinct modules and were used to deliver capacity building training during the years 2016, 2017, 2018, and 2019. These modules covered theoretical and hands-on knowledge on subjects such as climate data analysis, land use, land cover, crops, glacier mapping and monitoring, hydrological modelling, advanced RS and GIT applications, and WebGIS application development. Overall, five modules were 
designed under AFS themes, serving two for OJT and three for ST; twelve modules were designed under WRHD and LULC\&E themes, including one each for OJT and ToT respectively. The WCS themes consisted of only one module owing to a single service (i.e., SALDAS), while the crosscutting themes incorporated nine distinct modules serving six for ST, one each for OJT and ToT, and two for exposure and learning activities.

\subsubsection{Strengthening Institutional and Individual Capacity}

During the past four years, SERVIR-HKH has organized 62 capacity building events in the HKH region (Table 14.2). Overall, 1354 participants benefited from these activities, including professionals, policymakers, decision makers, and youth, representing 290 distinct institutions in the region and beyond. The participants represented various government ministries, organizations, institutions, local departments and offices, research centers, academic institutions, the private sector, and INGOs and NGOs. The breakdown of the events goes thus: one in 2016; 19 each in 2017 and 2018; and 23 in 2019. Among them, five each were under TOT and OJT; eight under the exposure and learning segment; and 44 under ST. Although the number of OJT and ToT events were less during the four years, yet they were effective in strengthening the institutional capacity of the partner organizations as these were targeted at specific applications for setting up self-managed information systems to meet organizational requirements. The OJTs were focused on professionals of partner institutions from Bangladesh, Afghanistan, and Nepal; and these trainings dealt with glacial lake mapping, drought mapping and monitoring, and WebGIS development. As for the ToTs, they helped to enable the trainers to conduct independent courses and transfer the knowledge to a wider audience.

The SERVIR program has successfully trained professionals and faculties from various institutions in three countries: Nepal's Agriculture and Forestry University, Kathmandu University, Tribhuvan University, and Pokhara University; Afghanistan's Kabul University; and Bangladesh's Jahangirnagar University. The broad topics and theories that were covered included advancement in the applications of GIT and EO in water resource management, the application of SAR, and big data analysis using GEE. At present, the OJT and TOT segments are serving as the core part of the capacity development activities in the region which are to be taken forward and replicated by the partners and professionals in the respective countries. For example, Kabul University, independently and in collaboration, has organized nearly 10 trainings on the topics of land cover mapping and monitoring, and water resource management (Box 14.1), while the Pashchimanchal Campus of Tribhuvan University organized a training in 2019 on SAR and GEE for the graduating students. Similarly, Jahangirnagar University organized a training in GEE in Dhaka in 2019. 
Table 14.1 The development of theme-based capacity building materials (2016-2019)

\begin{tabular}{|c|c|c|c|c|}
\hline $\mathrm{S} / \mathrm{N}$ & Module subject & Theme & $\begin{array}{l}\mathrm{CB} \\
\text { type }\end{array}$ & Material \\
\hline 1. & $\begin{array}{l}\text { Climate data analysis for drought } \\
\text { monitoring }\end{array}$ & AFS & ST & $\begin{array}{l}\text { PPT, manual, hands-on } \\
\text { tutorials }\end{array}$ \\
\hline 2. & $\begin{array}{l}\text { Agriculture information system } \\
\text { (irrigation portal) }\end{array}$ & AFS & ST & PPT, hands-on tutorials \\
\hline 3. & $\begin{array}{l}\text { WebGIS application } \\
\text { development }\end{array}$ & AFS & OJT & PPT, hands-on tutorials \\
\hline 4. & Crop mapping & AFS & OJT & PPT, hands-on tutorials \\
\hline 5. & $\begin{array}{l}\text { FEWS NET for } \\
\text { agro-climatological analysis }\end{array}$ & AFS & ST & PPT, hands-on tutorials \\
\hline 6. & Hydrological modeling & WRHD & ST & $\begin{array}{l}\text { PPT, manual, hands-on } \\
\text { tutorials }\end{array}$ \\
\hline 7. & $\begin{array}{l}\text { Mapping and monitoring of } \\
\text { glaciers }\end{array}$ & WRHD & $\begin{array}{l}\text { ST, } \\
\text { OJT }\end{array}$ & $\begin{array}{l}\text { PPT, manual, hands-on } \\
\text { tutorials }\end{array}$ \\
\hline 8. & VIC modeling & WRHD & ST & PPT, hands-on tutorials \\
\hline 9. & $\begin{array}{l}\text { RS and GIS for water resource } \\
\text { management }\end{array}$ & WRHD & $\begin{array}{l}\text { ST, } \\
\text { ToT }\end{array}$ & $\begin{array}{l}\text { PPT, manual, hands-on } \\
\text { tutorials }\end{array}$ \\
\hline 10. & RS of snow water resources & WRHD & ST & PPT, hands-on tutorials \\
\hline 11. & Streamflow forecasting tools & WRHD & ST & PPT, hands-on tutorials \\
\hline 12. & $\begin{array}{l}\text { Ecosystem services using the } \\
\text { ARIES platform }\end{array}$ & LULC\&E & ST & PPT, hands-on tutorials \\
\hline 13. & Land cover and land use mapping & LULC\&E & $\begin{array}{l}\text { ST, } \\
\text { ToT }\end{array}$ & $\begin{array}{l}\text { PPT, manual, hands-on } \\
\text { tutorials }\end{array}$ \\
\hline 14. & MRV-REDDcompass & LULC\&E & ST & PPT, hands-on tutorials \\
\hline 15. & Tree cover estimation & LULC\&E & OJT & PPT, hands-on tutorials \\
\hline 16. & SAR for forest monitoring & LULC\&E & ST & PPT, book, hands-on tutorials \\
\hline 17. & Land cover monitoring system & LULC\&E & ST & PPT, hands-on tutorials \\
\hline 18. & SALDAS & WCS & ST & PPT, hands-on tutorials \\
\hline 19. & SRTM-2 DEM applications & $\mathrm{CC}$ & ST & PPT, hands-on tutorials \\
\hline 20. & Sentinel satellite data analysis & $\mathrm{CC}$ & ST & PPT, hands-on tutorials \\
\hline 21. & GIS application development & $\mathrm{CC}$ & OJT & PPT, hands-on tutorials \\
\hline 22. & Google Earth Engine & $\mathrm{CC}$ & $\begin{array}{l}\text { ST, } \\
\text { ToT }\end{array}$ & PPT, hands-on tutorials \\
\hline 23. & Empowering women in GIT & $\mathrm{CC}$ & ST & PPT, hands-on tutorials \\
\hline 24. & $\begin{array}{l}\text { Agriculture and disaster } \\
\text { monitoring in the } \mathrm{HKH} \\
\text { (AOGEOSS) }\end{array}$ & $\mathrm{CC}$ & ST & $\begin{array}{l}\text { PPT, manual, hands-on } \\
\text { tutorials }\end{array}$ \\
\hline 25. & GWF, GFOI & $\mathrm{CC}$ & EL & PPT \\
\hline 26. & NASA SpaceApp, Miss Tech & $\mathrm{CC}$ & EL & $\mathrm{R} \& \mathrm{D}$ prototype demo \\
\hline 27. & Connecting space to village & $\mathrm{CC}$ & ST & PPT, hands-on tutorials \\
\hline
\end{tabular}


Table 14.2 Institutional and individual capacity building (2016-2019)

\begin{tabular}{|c|c|c|c|c|c|}
\hline Fiscal year & Event type & No. of events & Male $(\%)$ & Female $(\%)$ & Total \\
\hline 2016 & ST & 1 & 63.63 & 36.36 & 22 \\
\hline \multirow[t]{4}{*}{2017} & OJT & 1 & 83.33 & 16.67 & 6 \\
\hline & ToT & 1 & 100.00 & 0.00 & 4 \\
\hline & ST & 13 & 74.82 & 25.18 & 278 \\
\hline & EL & 4 & 54.05 & 45.95 & 185 \\
\hline Total & & 19 & 67.02 & 32.98 & 473 \\
\hline \multirow[t]{4}{*}{2018} & OJT & 3 & 90.00 & 10.00 & 10 \\
\hline & ToT & 1 & 75.00 & 25.00 & 8 \\
\hline & ST & 14 & 60.88 & 39.12 & 478 \\
\hline & EL & 1 & 90.00 & 10.00 & 10 \\
\hline Total & & 19 & 62.25 & 37.75 & 506 \\
\hline \multirow[t]{4}{*}{2019} & OJT & 1 & 100.00 & 0 & 6 \\
\hline & ToT & 3 & 83.33 & 16.67 & 36 \\
\hline & $\mathrm{ST}$ & 16 & 72.44 & 27.56 & 283 \\
\hline & EL & 3 & 78.57 & 21.43 & 28 \\
\hline Total & & 23 & 74.22 & 25.50 & 353 \\
\hline Overall & & 62 & 67.13 & 32.87 & 1,354 \\
\hline
\end{tabular}

ST Standard training; OJT On-the-job training; TOT Training of trainers; EL Exposure and learning

The analysis shows variations in the participation of men and women-67\% men and 33\% women. And in terms of women's representation in the years 2016, 2017, 2018, and 2019, the statistics show percentages of 36, 33, 38, and 26, respectively. The significant increase by $5 \%$ in 2018, as compared to 2017 , demonstrates the successful integration of ICIMOD's gender strategy into SERVIR-HKH's action plan (ICIMOD 2017). In contrast, there was a significant decline, by $12 \%$, during 2019 , as compared to 2018 ; this could be attributed to various factors, including the postponement of some women-focused activities to be held in Afghanistan in 2019. Also, the fact remains that there are fewer women professionals working in the GIT sector in the HKH region.

\subsubsection{Strengthening Service Area Capacity}

Under the various service areas (Fig. 14.3), the highest number (21) of events were organized under the crosscutting areas; these served 618 individuals and saw the participation of 210 institutions. Among the four thematic service areas, the WRHD segment organized 16 capacity strengthening events and served 321 participants from 36 institutions. As for the LULC\&E and AFS service areas, they served 60 and 43 institutions, respectively; while the LULC\&E segment provided various 


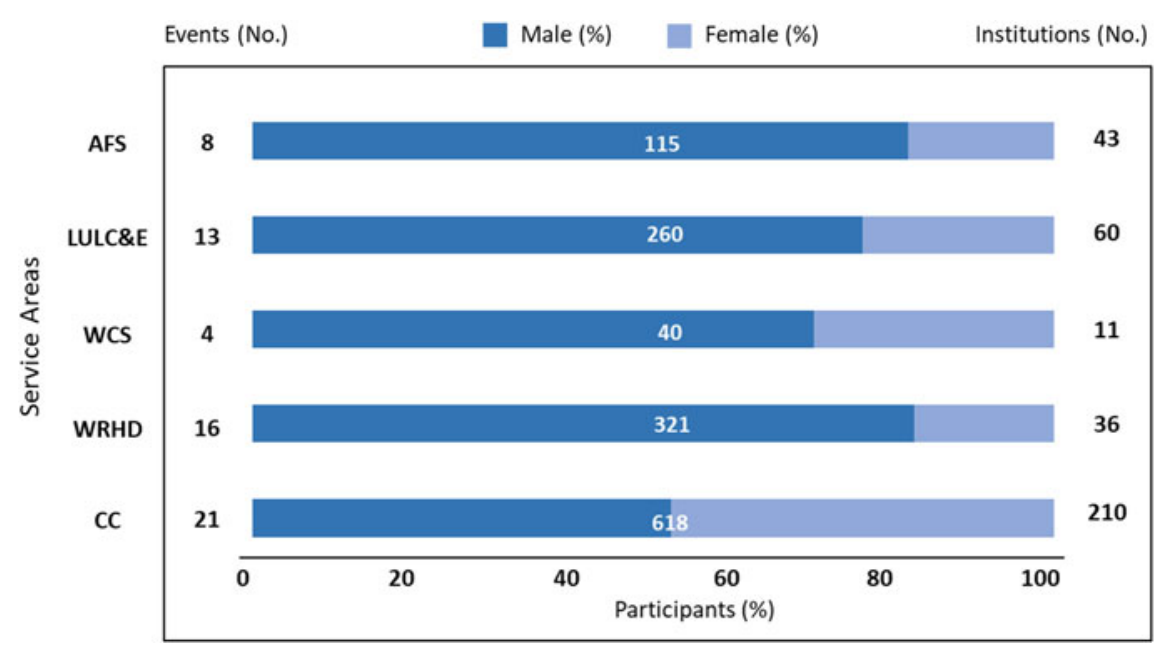

Fig. 14.3 Service area-based capacity building events. Note: The number displayed over each bar depicts total number participants

trainings to 260 individuals, the AFS segment catered to 115 individuals. The lowest number of activities was recorded by the WCS service, which tended to 11 institutions and their 40 professionals. Among the participants, the gender gap was found to be wider in the AFS and WRHD (<20\% of female participants) segments as compared to the LULC\&E and WCS service areas; this was despite several efforts and measures being taken to bring in more women participants to the training programs. Here, it has to be noted that the participants in these service areas were selected based on institutional nominations and that these institutions have less women professionals working in them. Interestingly, the crosscutting areas had the best gender balance, with the participation rate of women at $48 \%$; this might have been because some of the events in the crosscutting areas were open to all who met the minimum criterion and they did not require nominations.

\subsubsection{Capacity Building Outreach to Institutions and Country}

Although the major capacity building events were focused on Afghanistan, Bangladesh, Nepal, and Pakistan under the SERVIR-HKH program, the other four regional member countries of ICIMOD (Myanmar, Bhutan, China, and India) and 20 other countries also benefited from the capacity building activities (Table 14.3). Out of the total 62 events, Nepal participated in 36, followed by Afghanistan in 28, Bangladesh in 19, Pakistan in 11, Bhutan in nine, and India and Myanmar in eight each. Other countries, too, participated significantly in 16 events, sending 76 
Table 14.3 Country-wise participation in capacity building activities

\begin{tabular}{l|l|l|l|l|l}
\hline Country & Events & Institutions & Male $(\%)$ & Female $(\%)$ & Total \\
\hline Afghanistan & 28 & 26 & 88.78 & 11.22 & 392 \\
\hline Bangladesh & 19 & 52 & 73.29 & 26.70 & 161 \\
\hline Bhutan & 9 & 6 & 76.47 & 23.52 & 17 \\
\hline China & 2 & 3 & 60 & 40.00 & 5 \\
\hline India & 8 & 10 & 64.71 & 35.29 & 17 \\
\hline Myanmar & 8 & 18 & 58.14 & 41.86 & 43 \\
\hline Nepal & 36 & 130 & 52.11 & 47.89 & 616 \\
\hline Pakistan & 11 & 17 & 77.78 & 22.22 & 27 \\
\hline Others & 16 & 39 & 63.16 & 36.84 & 76 \\
\hline
\end{tabular}

${ }^{\mathrm{a} O t h e r s ~ i n c l u d e: ~ A u s t r a l i a, ~ B r a z i l, ~ C a n a d a, ~ G e r m a n y, ~ F i n l a n d, ~ F r a n c e, ~ G a b o n, ~ U n i t e d ~ K i n g d o m, ~}$ Guatemala, Italy, Kenya, Cambodia, Mongolia, Malawi, Mozambique, Netherlands, Papua New Guinea, Thailand, United States, and Vietnam

participants from 39 institutions. As for the overall participation count, country-wise, Nepal registered the highest number, with 616 people from 130 institutions. This high rate of participation has to do with the fact that Nepal hosted more events than any other country. Afghanistan was second, with 392 participants from 26 institutions. As for Bangladesh, it took part in 19 events, sending 161 participants from 52 institutions, the second highest by way of institutional representation. In terms of gender balance, Nepal again captured the first place, with over $48 \%$ of the representation from women. This has largely to do with women-focused events like "Miss Tech" and "Empowering Women in Geospatial Information Technology" (ICIMOD 2018, 2019a) which have greatly encouraged women to be more active participants in the whole technological enterprise. As regards other countries in terms of female representation, Myanmar, China, and India registered over $35 \%$ participation, while Bangladesh, Bhutan, and Pakistan recorded a participation level that was below 30\%. Afghanistan stood last in the gender balance list, with only $11 \%$ of its representatives being women. This has to do with the fact that less number of Afghan women are engaged in the GIT sector and there's also a reluctance to travel due to certain social norms.

The agile development of GIT and EO technologies demands continuous and sustainable capacity building activities; this, in turn, requires higher educational institutions to be the focus of capacity building efforts wherein they also become knowledge-sharing platforms. So, there is an imperative need to strengthen the capacity of the universities to facilitate research in these areas and to provide training. Realizing such needs, SERVIR-HKH has collaborated with partner universities and supported curriculum development in geoinformation science for running bachelor's and master's programs. It has helped in the introduction of master's programs in GIS and Remote Sensing, in Nepal Open University, Tribhuvan University, and Jahangirnagar University. Besides, it is supporting Kabul University in developing a bachelor's program in GIS. 


\subsubsection{Focus on Women and Underprivileged Communities}

Despite the profound infiltration of GIT and EO in its planning and decision-making processes, the concepts are still rudimentary or nonexistent in school education across the HKH region. A lack of skilled human resources and institutional capacities and gaps in communication hinder schoolteachers from introducing these concepts and their applications to students. In this regard, in 2019, SERVIR-HKH introduced a novel capacity building program called "Connecting Space to Village" to address the needs of the village communities. Under this theme, it organized a teachers' training program in 2019 which focused on imparting GIT knowledge to the local communities. This event brought together 19 high-schoolteachers from nine schools located in different parts of Nepal; the specific aim was to train these teachers on the use of SERVIR-HKH EO and GIT application services and data so that they could transfer this knowledge to school students and the local communities.

As regards having a gender-balanced workforce in the region, SERVIR-HKH has initiated a specially designed capacity building program for targeted groups of young and early career women of Nepal. This program was held in 2018 and 2019 and brought together young women from different backgrounds. These events saw theoretical and hands-on exercises on the use of EO and GIT which covered a range of topics, including the four thematic service areas of SERVIR. The replication of this initiative is now being sought by Bangladesh, Afghanistan, and Pakistan. And, as previously mentioned, ICIMOD also supported the holding of "Miss Tech 2017" in Kathmandu, a major national competition aimed at promoting techno-entrepreneurship among women; the theme of this particular event was "Transformational Changes through Technology". Such initiatives have not only helped women in starting and navigating their geospatial careers but also geared them towards providing leadership in the field of GIT.

\subsubsection{Monitoring and Evaluation of Capacity Building Activities}

For the evaluation of the capacity building activities, we targeted short-term monitoring to assess the knowledge gained by the participants; it also evaluated the success and shortcomings of the implementation procedure. This gave a broad picture about the experience of the participants. An evaluation response case as an example is presented here from a training on "Introductory Course on Synthetic Aperture Radar", which aimed to provide theoretical and practical knowledge on SAR data and its applications for crop monitoring in Afghanistan. The training, delivered by two resource persons from ICIMOD, was attended by 10 professionals from three institutions in Afghanistan. This seven-day training covered the following aspects: image formation; polarimetric SAR; backscattering mechanisms; 
Table 14.4 Responses (in \%) of the participants on the quality (an example from the training on SAR)

\begin{tabular}{l|l|l|l|l|l|l}
\hline S/N & Relevance & $\begin{array}{l}\text { Extremely } \\
\text { high }\end{array}$ & High & Medium & Low & $\begin{array}{l}\text { Not } \\
\text { at } \\
\text { all }\end{array}$ \\
\hline 1 & $\begin{array}{l}\text { The presentation was clear and } \\
\text { to the point }\end{array}$ & 60 & 30 & 10 & 0 & 0 \\
\hline 2 & The training was interactive & 60 & 40 & 0 & 0 & 0 \\
\hline 3 & $\begin{array}{l}\text { The presenter(s)/facilitator(s) } \\
\text { were highly knowledgeable } \\
\text { about the subject matter }\end{array}$ & 70 & 30 & 0 & 0 & 0 \\
\hline 4 & $\begin{array}{l}\text { The training achieved its goals } \\
\text { and objectives }\end{array}$ & 50 & 40 & 10 & 0 & 0 \\
\hline 5 & $\begin{array}{l}\text { The materials/handouts were } \\
\text { useful }\end{array}$ & 40 & 50 & 10 & 0 & 0 \\
\hline 6 & $\begin{array}{l}\text { The presentations were } \\
\text { interesting and practical }\end{array}$ & 50 & 40 & 10 & 0 & 0 \\
\hline 7 & $\begin{array}{l}\text { Adequate time was provided for } \\
\text { attendee questions }\end{array}$ & 40 & 40 & 20 & 0 & 0 \\
\hline 8 & $\begin{array}{l}\text { The content was well organized } \\
\text { and easy to follow }\end{array}$ & 40 & 40 & 20 & 0 & 0 \\
\hline 9 & $\begin{array}{l}\text { The training met my } \\
\text { expectations }\end{array}$ & 20 & 60 & 20 & 0 & 0 \\
\hline 10 & $\begin{array}{l}\text { Appreciation of the coffee } \\
\text { break and lunch }\end{array}$ & 70 & 30 & 0 & 0 & 0 \\
\hline
\end{tabular}

sensitivity of radar signals to moisture; radiometric and geometric distortions; processing of SAR data; and various applications of SAR data (ICIMOD 2019b). Table 14.4 presents the overall response of the participants.

As can be seen from Table 14.4, on several parameters, $90 \%$ of the participants described the relevance of the training as "extremely high" and "high"; this reflects the success of the whole program. And as to whether the participants had increased their capacity, skill, knowledge, and application ability, the response was cent per cent positive (Fig. 14.4a). The sessions on self-assessment and technical skills also showed positive results as we could see that the participants had indeed been able to learn significantly from them. During the pre-evaluation stage before the self-assessment session, $7 \%$ of the participants had stated that they possessed advanced knowledge, 21\% had described their knowledge as "intermediate", $31 \%$ had described it as "basic", while 40 had acknowledged that they possessed no knowledge at all in the area. However, these percentages improved significantly after the training program as $21 \%$ of the trainees stated that their knowledge and skills had reached an advanced stage, while $31 \%$ of them described their knowledge level as "intermediate". 
a

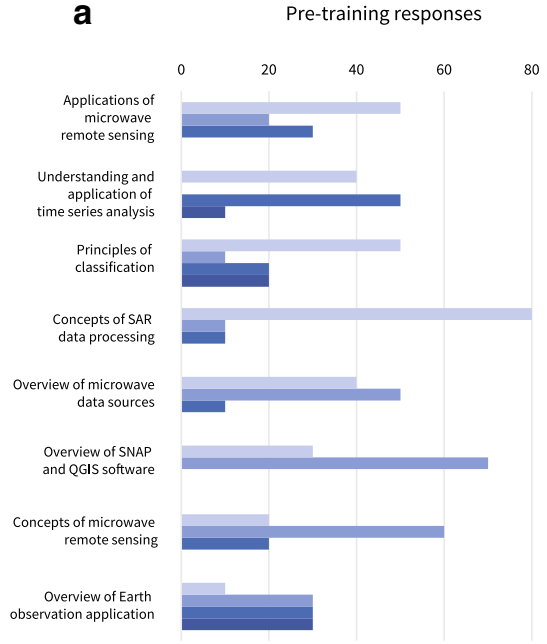

Post-training responses

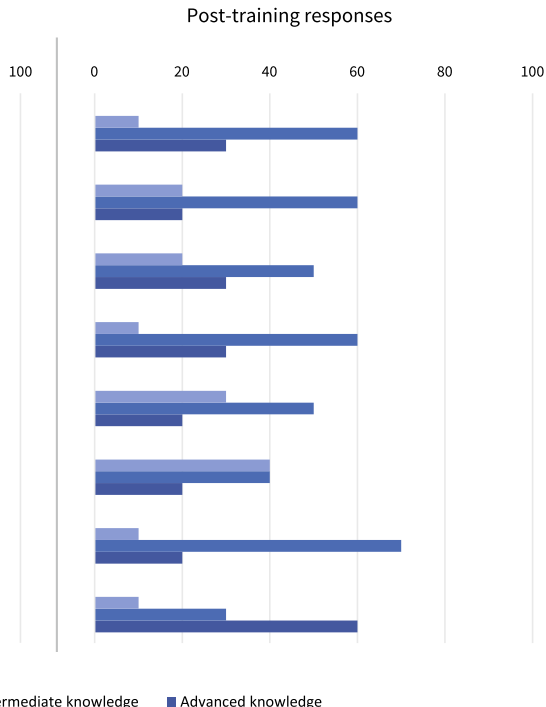

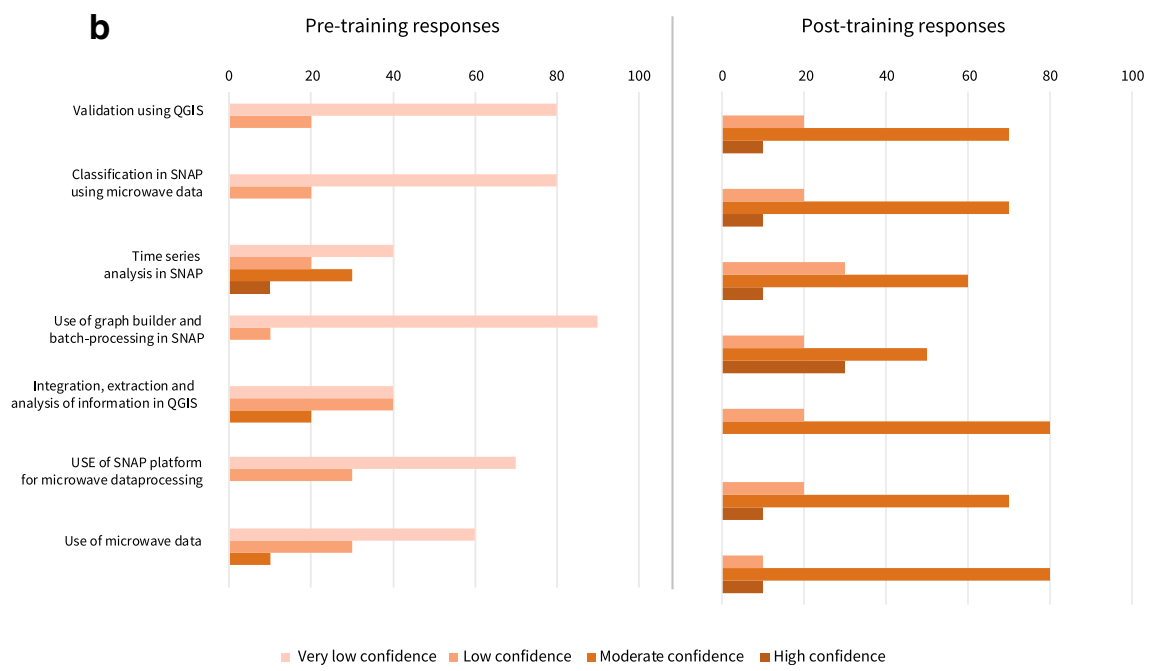

Fig. 14.4 a Depiction of pre- and post-training responses of participants on various themes under the self-assessment category. $\mathbf{b}$ Depiction of pre- and post-training responses of the participants on various themes under the technical skills category

As regards the technical skills segment of the training, before the program, only $1 \%$ of the participants had described their confidence level as "high", $8 \%$ had said they were "relatively confident", $28 \%$ had stated they possessed basic skills, while $65 \%$ had acknowledged that they had no skills at all (Fig. 14.4b). But the post-training evaluation reflected a positive leap in these figures, with $10 \%$ of the 
trainees saying that their confidence level was high, while $60 \%$ stated that their confidence level had improved. More remarkably, approximately $65 \%$ of the participants who had come to the training without any skills stated that after the training, they had acquired basic knowledge and that their confidence level was better.

\section{Adopting Capacity Building}

Transferring knowledge is the key part of any capacity development activity that helps the target group achieve short- and long. term goals. In this context, SERVIR-HKH provides various trainings to bridge the capacity gaps in the GIT and EO fields. The success of these trainings can be observed by the adoption and implementation of capacity building activities by partner institutions, professionals, and faculties.

A. Training on land use/land cover mapping using remote sensing and GIS

This five-day training programme, held in Kabul University, brought together 23 students from three faculties - of geoscience, environmental science, and agriculture - of Kabul University. The training mainly focused on the use of EO and GIT applications for land cover mapping in Afghanistan and covered basic concepts of land use and land cover (LULC) mapping, remote sensing, image classification, land cover classification, and applications of land cover mapping.

B. Training workshop on Earth observation and geospatial technologies for water resources management in Afghanistan

This was a 10-day event that brought together 38 lecturers from Nangarhar, Laghman, and Kunar universities of Afghanistan. They represented the faculties of agriculture, engineering, computer science, geology, and geography. The training covered basic concepts of water resource management, theoretical and practical understanding of RS and GIS applications in watershed and drainage delineations, generation of meteorological data, and hydrological modeling.

Box 14.1. A snapshot of institutional capacity building activities in Afghanistan

\subsection{Challenges and Opportunities}

In this chapter, we have presented the approach that has been adopted for building the capacity of individuals and organizations in EO and GIT applications in the HKH region; we have mentioned that, over the last four years, we conducted 62 events successfully in this area of capacity building. Some institutional success stories, such as establishing a GIS Lab, preparing a glacier data inventory, and many more are documented in http://servir.icimod.org/stories. However, there are several challenges ahead; there are also several opportunities that are waiting to be tapped (Table 14.5). 
Table 14.5 Key challenges and opportunities

\begin{tabular}{l|l}
\hline Challenges & Opportunities \\
\hline Collaboration with stakeholders & \multicolumn{2}{|l}{} \\
\hline $\begin{array}{l}\text { - Bringing key stakeholders to country } \\
\text { consultations and prioritizing capacity } \\
\text { needs }\end{array}$ & $\begin{array}{l}\text { Bringing stakeholders closer and engaging } \\
\text { in the assessment of capacity building gaps } \\
\text { and needs }\end{array}$ \\
$\begin{array}{l}\text { Getting policy-level personnel to provide } \\
\text { wider inputs on gaps and needs }\end{array}$ & $\begin{array}{l}\text { Preparing a priority list to design activities } \\
\text { and implementation }\end{array}$ \\
\hline
\end{tabular}

Emerging EO and GIT techniques

- Frequent updating of the capacity of individuals and institutions

- Cost-effective choices on:

New curriculum, materials, and programs on capacity building

- Resource stress and lack of availability of appropriate SMEs

- Training material development and implementing capacity building activities

- Availability of open-access tools and data for individuals and institutions

- Acquiring cutting-edge expert knowledge by engaging SMEs

\section{Capacity building events}

- Irrelevant nominations for highly technical - Enabling a variety of people - from youth to trainings

- Difficulties in ensuring gender balance

- Geopolitical tension among the regional member countries professionals and technicians - to set policy agendas for the larger benefit of society Multiplying the effects of learning, adding value to knowledge, and instilling a greater sense of ownership among the stakeholders

\section{Women's participation}

- Less women professionals in the EO GIT fields

- Social and religious obligations hindering women's participation

- Designing women-focused capacity building programs

- Nurturing a gender-balanced workforce

Monitoring and evaluation

Participants' reluctance to provide true responses and a lack of motivation to respond to survey questionnaires
- Understanding the expectations and learning from the achievements

- Tracing the impact of an activity and taking the necessary measures to improve it

\section{Sustainability}

- Staff turnover at partner institutions

- Problem in the continuation of services and plans because of the finite nature of projects
- Ensuring an overlap between outgoing and incoming staff, and transferring knowledge to retain capacity

- Conducting periodic refresher trainings to bring the new staff up to the mark

- Engaging with the senior management to promote the utilization of the new knowledge for decision-making

\section{Others}

- Language barrier

- Retaining professionals for long term
- Interacting with people from diverse social backgrounds

- Forging stronger partnerships and professional networks 
Adopting online virtual capacity building in SERVIR-HKH

The COVID-19 pandemic has seen SERVIR-HKH adopting online learning methods and strengthening the capacity in this area. The online platforms that have been used are: Microsoft Teams, Zoom, AWS Cloud, and edX. In this regard, SERVIR-HKH organized a training programme on "Empowering Women in GIT", from 19-22 May 2020. Twenty-five women from across Nepal and Australia attended the training for four days with a singular focus - to expand their knowledge and skills in GIT. The programme involved women-focused training events to help women students and professionals make a career in the GIT field. The training was conducted remotely via the Microsoft Teams platform. The presentations, resource materials, and session recordings were made available via Microsoft Teams so that the participants could refer to them and strengthen their knowledge base.

Box 14.2. Adoption of online capacity building activities

\subsection{Conclusion and Way Forward}

Increasing the influence and potential of EO data and GIT for making geographically informed decisions in resource planning has been a much sought-after goal in the HKH region. The rapid developments and new paradigms on EO and GIT applications, the lack of skilled human resources and institutional capacities in the region demand robust capacity building activities to reap the benefits of these applications. This chapter has presented in detail the ADIM - assessment, design, implementation, and monitoring - framework adopted by SERVIR-HKH in strengthening capacity enhancing activities. Through this approach, we have been able to identify the gaps and needs, design efficient capacity building programs, implement plans to achieve lasting impacts, and monitor the results. In this regard, we have not only engaged with subject matter experts but also decision makers for the efficient application of these frontier technologies. We have also given priority to gender equity. While the challenges have been aplenty, our programs such as ToT, OJT, ST, and EL have played an instrumental and significant role in strengthening the capacities of individuals from all levels as well as institutions and organizations on the use of these emerging technologies. We have also integrated the M\&E approach to gather regular feedback, thereby improving the overall quality of the capacity building ventures. We believe that by sharing our experiences, we are widening the knowledge pool for the capacity building practitioners in the HKH region and beyond. However, there is a lot more that needs to be done in this vital area of capacity building. In the upcoming years, the following areas could be looked at:

- Applying uniform formats for training manuals and materials among the service areas;

- Conducting virtual trainings and organizing distance learning capacity building events through digital platforms such as Microsoft Teams, Zoom. AWS Cloud, and edX; 
- Developing a web portal with self-learning training materials which will not only help enhance the capacities in the region but also beyond;

- Prioritizing the use of open-source GIS/RS software; and

- Conducting regular organizational capacity assessments and tracer surveys to monitor the impacts of the capacity building efforts and to identify the emerging needs in the region.

\section{References}

Chandler J, Kennedy KS (2015) A network approach to capacity building. National Council of Nonprofits, Washington, DC. Available online at: www.councilofnonprofits.org

Flores A, Herndon K, Thapa RB, Cherrington E (eds) (2019) SAR handbook: comprehensive methodologies for forest monitoring and biomass estimation. NASA Publication. https://doi. org/10.25966/nr2c-s697, 307 pages

GEF (Global Environment Facility) (2003) Strategic approach to enhance capacity building. GEF ICIMOD (2017) Fourth medium-term action plan 2018-2022. Available online at: https://www. icimod.org/resource/30287. Accessed 30 May 2019

ICIMOD (2018) Empowering women in GIT. Training report, Kathmandu, Nepal, 25-28 June 2018

ICIMOD MTAP-IV Medium-Term Action Plan (2018-2022)

ICIMOD (2019a) Empowering women in GIT. Training report, Kathmandu, Nepal, 25-28 June 2019

ICIMOD (2019b) Introductory course on synthetic aperture radar. Training report, Delhi, India, 15-21 April 2019

Ingole NA, Ram RN, Ranjan R, Shankhwar AK (2015) Advance application of geospatial technology for fisheries perspective in Tarai region of Himalayan state of Uttarakhand. Sustain Water Res Manag 1(2):181-187. International Disaster Database: www.cred.be

Leibrand A, Thomas A, Sadoff N, Maslak T (2019) Using Earth observations to help developing countries improve access to reliable, sustainable and modern energy. Front Environ Sci 7:123

Manfré LA, Hirata E, Silva JB, Shinohara EJ, Giannotti MA, Larocca AP, C et al (2012) An analysis of geospatial technologies for risk and natural disaster management. ISPRS. Int J Geo-Inform 1:166-185. https://doi.org/10.3390/ijgi1020166

Nelson EJ, Pulla ST, Matin MA, Shakya K, Jones N, Ames DP, Ellenburg WL, Markert KN, David CH, Zaitchik BF, Gatlin P (2019) Enabling stakeholder decision-making with Earth observation and modeling data using Tethys platform. Front Environ Sci

Ofori-Amoah B (2008) Building capacity to use geospatial technology for development in Africa: lessons from the Uganda GIS project. Global dialogue on emerging science and technology (GDEST) Cape Town, South Africa, pp 2001-2009

Ortiz A, Taylor P (2009) Learning purposefully in capacity development. Why, what and when to measure, vol 1, p 49

Potter C, Brough R (2004) Systemic capacity building: a hierarchy of needs. Health Policy Plan 19:336-345. https://doi.org/10.1093/heapol/czh038

Revenga C (2005) Developing indicators of ecosystem condition using geographic information systems and remote sensing. Reg Environ Chang 5:205-214

Scott G, Rajabifard A (2017) Sustainable development and geospatial information: a strategic framework for integrating a global policy agenda into national geospatial capabilities. Geo-Spat inform Sci 20(2):59-76 
Shrestha B, Bajracharya B (2002) GIS education - experiences from the Hindu Kush-Himalayan $(\mathrm{HKH})$ region. In: Proceedings of the 23rd Asian conference on remote sensing, Kathmandu, Nepal

Thapa RB, Itoh T, Shimada M, Watanabe M, Motohka T, Shiraishi T (2014) Evaluation of ALOS PALSAR sensitivity for characterizing natural forest cover in wider tropical areas. Remote Sens Environ 155:32-42

Thapa RB, Motohka T, Watanabe M, Shimada M (2015) Time-series maps of aboveground carbon stocks in the forests of central Sumatra. Carbon Balance Manage 10(23):1-13. https://doi.org/ 10.1186/s13021-015-0034-5

Thapa RB, Matin MA, Bajracharya B (2019) Capacity building approach and application: utilization of Earth observation data and geospatial information technology in the Hindu Kush Himalaya. Front Environ Sci 7:165

Tripathi P, Thapa RB (2019) Efforts on gender balance capacity building in GIT. Int Arch Photogrammetry Remote Sens Spatial Inform Sci 42:149-152

UNDP (2008) Supporting capacity development: the UNDP approach. United Nations Development Programme

Xia J, Lin L, Lin J, Nehal L (2014) Development of a GIS-based decision support system for diagnosis of river system health and restoration. Water 6(10):3136-3151

Open Access This chapter is licensed under the terms of the Creative Commons Attribution 4.0 International License (http://creativecommons.org/licenses/by/4.0/), which permits use, sharing, adaptation, distribution and reproduction in any medium or format, as long as you give appropriate credit to the original author(s) and the source, provide a link to the Creative Commons license, and indicate if changes were made.

The images or other third party material in this chapter are included in the chapter's Creative Commons license, unless indicated otherwise in a credit line to the material. If material is not included in the chapter's Creative Commons license and your intended use is not permitted by statutory regulation or exceeds the permitted use, you will need to obtain permission directly from the copyright holder. 